\title{
Probable subjective health hazards of mobile phone
}

Hisham M Mahaba, M.D*., Abd Elrahman Saed ${ }^{* *}$, Mishael M Alelyani Ph D ${ }^{* * *}$

*Professor of Public Health, Faculty of Applied Medical Sciences, King Khalid University, KSA

**Undergraduate student, Faculty of Applied Medical Sciences, King Khalid University, KSA

*** Applied Medical Sciences Khamis Misheat, King Khalid University

Received :January $2016 \quad$ accepted : March 2016

\section{Abstract}

Introduction: Although mobile phones are extensively used, few of its possible health hazards were studied. Many investigators studied the possible carcinogenic effects, however few gave attention to possible systemic health hazards of mobile phone. Objectives: This work was conducted to study the possible systemic effects of mobile phones. Subjects and Methods: This study was conducted during the period from $1^{\text {st }}$ of October to end of December 2015. A cross sectional survey was conducted to study possible health hazards of mobile phone. The study involved 692 students and employees at King Khalid University, Abha, KSA. An internet self administered questionnaire was used to collect data. Results: Tinnitus was heard after mobile use by 362(52\%) of subjects. 260 (37.6\%) felt hearing loss. In addition 505 (73\%) had insomnia during night. Lack of concentration was reported by 563 (81.4\%) of subjects. In addition 205 (29.6\%) suffered palpitation on increased use of mobile phone. Wrist pain was felt by $438(63.3 \%)$. Also $536(77.5 \%)$ felt neck pains at least occasionally. $117(16.9 \%)$ had pain in lower limb after keeping the mobile phone at their belts. $430(81.4 \%)$ of subjects complained of memory loss. Headache after mobile use was felt by $363(52.5 \%)$ subjects. Comparison between age groups showed that insomnia, tinnitus, and lack of concentration increased with age. Also insomnia, lack of concentration were more common among smokers. Leg pain was more common between smokers under 18 years of age. Conclusions: Possible subjective health hazards were frequently reported among mobile users. They included insomnia, lack of concentration, memory loss, palpitations, wrist pain and leg pains.

Keywords: Effects -Health-mobile- phone

Correspondence to Professor Dr Hisham Mahaba. e -mail: hmam1957@yahoo.com

\section{Introduction}

The effect of mobile phone electromagnetic radiation on human health is a question of interest and study worldwide, as a result of the vast increase in its usage worldwide. By November 2011, there were about 6 billion subscriptions globally. ${ }^{1}$ Mobile phones apply microwave range of electromagnetic radiation. Other devices used for data communication networks, produce similar radiation.
During 2011 International agency for Research on Cancer (IARC), classified mobile phone radiation as Group 2Bpossibly carcinogenic. That means that there "could be some risk" of carcinogenicity, so further research into the long-term, use of mobile phones should be conducted ${ }^{2}$. The WHO in June 2011 concluded that "to date, no adverse health effects have been established as being caused by mobile phone use", ${ }^{3}$ a point they repeated in October 2014. ${ }^{4}$ 
Several studies have investigated possible health symptoms of mobile phone. In 2007 the European Commission Scientific Committee on Emerging and Newly Identified Health Risks (SCENIHR) ${ }^{5}$ concluded that "exposure to RF fields is unlikely to lead to an increase in cancer in humans".

Local heat produced by radiofrequency waves was said to be unlikely to have harmful effects. The brain's blood circulation is capable of getting rid of excess heat by increasing local blood flow. Nevertheless, the cornea does not have this temperature regulation mechanism and cataracts in rabbits' eyes was reported at SAR values from 100-140 W/kg, which produced lenticular temperatures of $41{ }^{\circ} \mathrm{C}$. However there were no cataracts detected in the eyes of monkeys exposed to similar conditions. ${ }^{6}$ Premature cataracts have not been linked with cell phone in human.

Other effects like increased glucose metabolism within parts of the brain closest to phone antenna was reported. ${ }^{7,8}$ In addition leakage of albumen into the rat brain via a permeated bloodbrain barrier was reported..$^{9,10,11}$ Other researchers did not confirm these findings. ${ }^{12}$

One protein , HSP 27, played an important role in the integrity of the blood-brain barrier was affected. ${ }^{13}$

In 2006, a large study about the relation between mobile phone and cancer was published. It followed over 420,000 Danish citizens for 20 years. This study did not show any increased risk of cancer. $^{14}$ Consistent findings were found by other researchers. ${ }^{15}$ Another studies did not find a link between mobile phones and brain tumors, glioma or meningioma. ${ }^{16},{ }^{17}$
However a study suggested an increased risk of glioma at the highest exposure levels. ${ }^{18}$ In addition a Swedish team suggested that regular use of mobile phone for decades increased the risk of acoustic neuroma. ${ }^{19}$ Also the relation between use of mobile phone and malignant glioma, acoustic neuroma was found by other researchers. ${ }^{20}$ Moreover, it has been suggested that electromagnetic fields associated with mobile phones may play a role in speeding up the development of an existing cancer.

In 2009, a meta-analysis of 23 studies, found that "there is possible evidence" that mobile phone use causes an increased risk of tumors. ${ }^{21}$

A British study (2005) concluded that there is no substantial risk of acoustic neuroma in the first decade after starting mobile phone use. However, an increase in risk after longer term use could not be ruled out. ${ }^{22}$ Also other study (2006) did not find any increased risk of glioma or meningioma among cellular phone users; however, they suggested for long-term cellular phone users, results need to be confirmed before firm conclusions can be drawn. ${ }^{23}$ Other researchers came to the same conclusions. $^{24}$

Some users of mobile handsets have reported feeling of several unspecific symptoms, during and after its use; ranging from burning and tingling sensations in the skin of the head and extremities, fatigue, sleep disturbances, dizziness, , loss of mental attention, reaction time and memory retentiveness, headaches, malaise, tachycardia, and digestive disturbances. ${ }^{25}$

While a Finnish study failed to find any effect on sleep or other cognitive function, ${ }^{26}$ other papers found significant effects on sleep. ${ }^{27,28,29,30,31,32}$ 
As shown in this introduction, researchers gave more attention to study possible rare effects of RF waves used in mobile phone, like cancer rather than the probably more common systemic effects like palpitation, hypertension and insomnia etc. So this work will be done to study such possible health hazards.

\section{Objectives}

1. To explore a relation between exposure to mobile phone radiofrequency waves and systemic symptoms like tinnitus, insomnia, lack of concentration, pains, palpitation, and loss of memory felt by users.

2. To identify risk factors that could potentiate the effects of RF waves on human health, like age and smoking habits.

\section{Subjects and Methods}

A cross sectional survey was conducted at KKU, Faculty of Applied Medical Sciences for Males, Khamis Misheat, during the period between 1st of October to end of November 2015. The study involved University students, staff and employees at KKU. It included 700 persons. An internet self administered questionnaire was used to collect data. Google web browser program was used to distribute the questionnaire. QR maker and QR reader programs were used to facilitate internet access to the questionnaire. The QR code was sent to staff by WhatsApp mobile program and was printed and placed on entrances of main corridors at Faculty of Applied Medical Sciences Khamis.

Sample size were estimated to be 296 subjects, Using Epi info 7 program for $430(62.1 \%)$
Windows. Significant level were set at $95 \%$, power 0.80 and alpha type I error 0.05 , and type II error or beta 0.2. The prevalence of symptoms among unexposed was chosen as $50 \%$, and Odd's ratio equal to 2 . Out of 700 questionnaire received 692 ( $98.85 \%$ ) were complete.

Statistical analysis were done using Spss Statistical package for Windows, Portable PASW Statistics 18.

\section{Results}

The study involved 700 subjects that responded to the questionnaire.

Persons were enquired about systemic symptoms and history of car accidents. Questionnaires were complete in 692 $(98.85 \%)$ subjects. Missed variables were numerous in 8 questionnaires that were excluded from analysis.

Table 1, summarizes the systemic symptoms reported by studied subjects.

Auditory symptoms studied included sensation of tinnitus and hearing loss.

Tinnitus was reported by 362 (52.3\%) of subjects, and hearing loss was reported by 260 (37.6\%) persons.

As regards visual symptoms, dryness of eye was reported by $533(77 \%)$ persons.

Central nervous system symptoms studied included insomnia, memory loss, lack of concentration and headache. Insomnia was a complaint of $505(73 \%)$ persons. Lack of concentration was reported by 563 $(81.4 \%)$ subjects. Memory loss was reported by 
subjects. $363(52.5 \%)$ persons suffered headache which they attributed to mobile phone use.

Tachycardia and palpitation was reported by 205 (29.6\%) persons.

So this study was done to explore the presence of those possible systemic effects mentioned. This cross section study found high percentage of different symptoms like, memory loss, deafness, tinnitus, leg pain, and car accidents among mobile users.

The extensive use of mobile caused it difficult to find a control group of non users. All those responded to our internet questionnaire were mobile phone users. So there were only one group of mobile users.

This study is considered an exploratory one with limitations that could affect its results. Those limitations include, lack of a control group, the nature of soft data obtained by questionnaire and the subjective symptoms which need further studies to define and verify.

Dryness of the eye may be due to deficiency in production of tears due to disease or to inefficient spread of tears and lubrication of the eye. In our study eye dryness was reported by $77 \%$ of subjects. The infrequent blinking during prolonged use of mobile phones may decrease lubrication of the eye and predispose to eye dryness. ${ }^{35}$

High percentages of CNS symptoms like insomnia, memory loss and lack of concentration among young people should raise also the possible role of mobile phone on brain, probably by brain tissue or blood vessels.

Leg pain was common among those keeping mobile phone at their belt level. Mobile could affect the great vessels
Pains in finger and wrist joint was complained by 438 (63.3\%) persons. 536( 77.5) suffered neck pains. Moreover 117(16.9\%) suffered pain in lower limb after keeping mobile at waist belt.

High percentages of hearing loss and tinnitus were found. They seem to be higher than that expected in general population of non users of mobile. A possible role mobile phone in predisposing to deafness and tinnitus should be raised and it could be due to effect of mobile phone on blood supply to the inner ear. Our results are consistent with previous results that related tinnitus to mobile use. ${ }^{33}$ The effects was attributed to exposure of cochlea to energy of radiOfrequency electromagnetic waves. In this later study it was mentioned that $10-15 \%$ of population suffer from tinnitus. This figure is lower than that found in our study of $52.3 \%$. Also hearing loss was reported by $37.6 \%$ of subjects which is much higher than expected in general population of $9 \%$ as reported by WHO. ${ }^{34}$

and nerves present in this area and supplying the lower limb.

Mobile phones radiate an average power of 0.2-0.6 W. When hand-held and operated close to the head 40 percent of radiated phone energy is absorbed in the hand and the head ${ }^{(37)}$. In this mode of operation, a mobile phone may be regarded as a quite powerful radio transmitter. Its emission at the head surface is typically 10,000 times stronger than fields reaching the head of a user standing within $30 \mathrm{~m}$ of the base of a typical mobile phone relay transponder mounted on a tower $30 \mathrm{~m}$ above ground." W. Ross Adey, International Encyclopedia of Neuroscience ${ }^{(37)}$.

Microwave signals travel through human tissue, glass, metal and plastic. 
Human tissue also absorbs microwave radiation. The effect of even minute levels of microwave radiation have been shown to, open the blood-brain barrier, heat head and brain tissue, disrupt brain activity, reverse cell membrane polarity, alter brain waves, alter brain chemistry, and damage DNA (37).

The effects of the radiation was shown to produce a wide range of physical

\section{Discussion}

Although the importance of studying mobile health hazards can't be overlooked because of its extensive worldwide use, relatively few studies were conducted to study its possible health hazards. Most of investigators were interested in determining the possible rare carcinogenic effects of electromagnetic radiation used by mobile 2,15,16,17,18,19,20,21,22,23.

However less attention was given to study more possible and more common possible health hazards to mobile phone like, auditory manifestations including deafness and tinnitus. Also cardiovascular manifestations like arrhythmias and peripheral vascular problems, and CNS manifestations like lack of concentration, memory loss, headache and insomnia. Also few investigatory reported pain in wrist, fingers, and neck following mobile use. 24

So this study was done to explore the presence of those possible systemic effects mentioned. This cross section study found high percentage of different symptoms like, memory loss, deafness, tinnitus, leg pain, and car accidents among mobile users.

The extensive use of mobile caused it difficult to find a control group of non users. All those responded to our internet questionnaire were mobile phone users. So there were only one group of mobile users. symptoms. Some symptoms may take years to show up. Some of the effects can be short-term while other effects can be long-term or permanent. These included, memory loss, headache, mood swings, lack of concentration, fatigue, sleep disorders and pains in hands or arms (37).

Cell Tower Radiation was shown to Cause Headaches and Nausea

This study is considered an exploratory one with limitations that could affect its results. Those limitations include, lack of a control group, the nature of soft data obtained by questionnaire and the subjective symptoms which need further studies to define and verify.

High percentages of hearing loss and tinnitus were found. They seem to be higher than that expected in general population of non users of mobile. A possible role mobile phone in predisposing to deafness and tinnitus should be raised and it could be due to effect of mobile phone on blood supply to the inner ear. Our results are consistent with previous results that related tinnitus to mobile use. 33 The effects was attributed to exposure of cochlea to energy of radiOfrequency electromagnetic waves. In this later study it was mentioned that $10-15 \%$ of population suffer from tinnitus. This figure is lower than that found in our study of $52.3 \%$. Also hearing loss was reported by $37.6 \%$ of subjects which is much higher than expected in general population of $9 \%$ as reported by WHO.34

Dryness of the eye may be due to deficiency in production of tears due to disease or to inefficient spread of tears and lubrication of the eye. In our study eye dryness was reported by $77 \%$ of subjects. The infrequent blinking during prolonged use of mobile phones may decrease lubrication of the eye and predispose to eye dryness. 35 
High percentages of CNS symptoms like insomnia, memory loss and lack of concentration among young people should raise also the possible role of mobile phone on brain, probably by brain tissue or blood vessels.

Leg pain was common among those keeping mobile phone at their belt level. Mobile could affect the great vessels and nerves present in this area and supplying the lower limb.

Mobile phones radiate an average power of 0.2-0.6 W. When hand-held and operated close to the head 40 percent of radiated phone energy is absorbed in the hand and the head (37). In this mode of operation, a mobile phone may be regarded as a quite powerful radio transmitter. Its emission at the head surface is typically 10,000 times stronger than fields reaching the head of a user standing within $30 \mathrm{~m}$ of the base of a typical mobile phone relay transponder mounted on a tower $30 \mathrm{~m}$ above ground." W. Ross Adey, International Encyclopedia of Neuroscience (37).

Microwave signals travel through human tissue, glass, metal and plastic. Human tissue also absorbs microwave radiation. The effect of even minute levels of microwave radiation have been shown to, open the blood-brain barrier, heat head and brain tissue, disrupt brain activity, reverse cell membrane polarity, alter brain waves, alter brain chemistry, and damage DNA (37).

The effects of the radiation was shown to produce a wide range of physical symptoms. Some symptoms may take years to show up. Some of the effects can be short-term while other effects can be long-term or permanent. These included, memory loss, headache, mood swings, lack of concentration, fatigue, sleep disorders and pains in hands or arms (37).

Cell Tower Radiation was shown to Cause Headaches and Nausea.

\section{Recommendations}

To reduce the risk of mobile phone the followings are recommended:

1.Use the mobile phone only in places with a strong signal. This allows the phone to transmit at low power (up to 100 times lower than its maximum value), reducing exposure accordingly.

2.Reduce the length of calls to a minimum.

3. Extend the antenna and hold it away from the head. Hold the phone away from your head whenever possible.

4.Use a hands-free kit and keep the phone away from head.

5.Use earphones made of fiber optic cable. Metal earphone wire can act as an antenna and direct radiation into the head from the ear canal.

\section{Recommendations}

To reduce the risk of mobile phone the followings are recommended:

1.Use the mobile phone only in places with a strong signal. This allows the phone to transmit at low power (up to 100 times lower than its maximum value), reducing exposure accordingly.

2.Reduce the length of calls to a minimum.

3. Extend the antenna and hold it away from the head. Hold the phone away from your head whenever possible.

4.Use a hands-free kit and keep the phone away from head.

5.Use earphones made of fiber optic cable. Metal earphone wire can act as an 
antenna and direct radiation into the head from the ear canal.

\section{References}

Feijoo C and Simon PJ. Innovation in mobile ecosystem. The AcornRedecom Conference, Brasilia May 1415,2010

IARC classifies radiofrequency electromagnetic fields as possibly carcinogenic to humans" (PDF). World Health organization press release No208 (Press release). International Agency for Research on Cancer. 31 May 2011.

WHO." Electromagnetic fields and public health: mobile phones-Fact sheet No 193. World health Organization June 2011. Archived from the original on 2011-08-14.

WHO."Electromagnetic fields and public health: mobile phones-Fact sheet No 193". World Health Organization. October 2014.

SCENIHR."Conclusions on mobile phones and radio frequency field". European Commission Scientific Committee on Emerging and Newly Identified Health Risks (SCENIHR). 9th plenary meeting at January 2015.

ICNIRP. International Commission on Non-Ionizing Radiation Protection (April 1998)." Guidelines For Limiting Exposure To Time-Varying Electric, Magnetic, And Electromagnetic Fields (up to $300 \mathrm{GHz}$ )" (PDF). Health Physics 74 (4): 494-505.

Volkow, Nora D.; Tomasi, Dardo; Wang, Gene-Jack; Vaska, Paul; Fowler, Joanna S.; Telang, Frank; Alexoff, Dave; Logan, Jean; et al. (2011). "Effects of Cell Phone Radiofrequency Signal Exposure on Brain Glucose metabolism". JAMA 305 (8): 808-13.

Press, Canadian (23 February 2011)."Cellphones linked to increased brain glucose metabolism". The Globe and Mail (Toronto).

Salford, Leif G.; Arne E. Brun; Jacob L. Eberhardt; Lars Malmgren; Bertil R.
R. Persson (June 2003). "Nerve Cell Damage in Mammalian Brain after Exposure to microwaves from GSM Mobile Phones". Environmental Health Perspectives (United States: National Institute of Environmental Health Sciences 111 (7): 881- 883.

Salford, Leif G.; Henrietta Nittby; Arne Brun; Gustav Grafstrom; Lars Malmgren; Marianne Sommarin; Jacob Eberhardt; Bengt Widegren; Bertil R. R. Persson (2008)." The Mammalian Bain In the Electromagnetic Fields Designed by Man with Special Reference to blood- brain barrier function, Neuronal Damage and Possible physical Mechanisms". Progress of Theoretical Physics Supplement (Japan: Physical Society of Japan) 173: 283-309. doi:10.1143/PTPS. 173. 283.

Frey, Allan (March 1998). "Headaches from cellular telephones: Are they real and what are the implications?" Environmental Health Perspectives 106 (3): 101-3.

Franke; et al. (2 September 2005). "Electromagnetic fields (GSM 1800) do not alter blood-brain barrier permeability to sucrose in models in vitro with high barrier tightness".Bioelectromagnetics 26 (7): 529-535. .

http://www.theguardian.com/uk/2002/j un/20/research.medicalscience.

Wikipedia. Mobile phone radiation and Health. 2016.

Schuz, J; Jacobsen, R; Olsen, JH; Boice, JD; Mc Laghlin, JK;Johansen, C (December 2006)." Cellular Telephone Use and Cancer risk: Update of "Cellular Telephone Use and Cancer risk: Update of a Nationwide Danish Cohort" . Journal of the National Cancer Institute 98 (23): 1707-1713.

Frei P."Use of mobile phones and risk of brain tumours: update of Danish cohort study" BMJ( 343), 2011. 
Lönn, Stefan; Ahlbom, Anders; Hall, Per; Feychting, Maria; Swedish Interphone Study Group (2005). "LongTerm Mobile Phone Use and Brain Tumor Risk". American Journal of Epidemiology 161 (6): 526-35.

Interphone Study Group (2010). "Brain tumour risk in relation to mobile telephone use: Results of the INTERPHONE international casecontrol study". International Journal of Epidemiology 39 (3): 675-694.

Lönn, Stefan; Ahlbom, Anders; Hall, Per; Feychting, Maria (2004). "Mobile Phone Use and the Risk of Acoustic Neuroma". Epidemiology 15 (6): 6539.

Hardell, Lennart; Carlberg, Michael; Söderqvist, Fredrik; Mild, Kjell Hansson; Morgan, L. Lloyd (2007). "Long-term use of cellular phones and brain tumors: Increased risk associated with use for more than 10 years". Occupational and Environmental Medicine 64 (9): 62632.

Myung, S.-K.; Ju, W.; McDonnell, D. D.; Lee, Y. J.; Kazinets, G.; Cheng, C.T.; Moskowitz, J. M. (13 October 2009). "Mobile Phone Use and Risk of Tumors: A Meta-Analysis". Journal of Clinical Oncology 27 (33): 5565-5572.

Schoemaker, M J; Swerdlow, A J; Ahlbom, A; Auvinen, A; Blaasaas, K G; Cardis, E; Christensen, H Collatz; Feychting, M; et al. (2005). " Mobile phone use and risk of acoustic neuroma: Results of the interphone case -control study in five North European countries". British Journal of Cancer 93 (7): 842-848.

Schüz, Joachim; Böhler, Eva; Berg, Gabriele; Schlehofer, Brigitte; Hettinger, Iris; Schlaefer, Klaus; Wahrendorf, Jürgen; Kunna-Grass, Katharina; et al. (2006). "Cellular Phones, Cordless Phones, and the Risks of Glioma and Meningioma (Interphone Study Group, Germany)". American
Journal of Epidemiology 163 (6): 512 20.

Lahkola, Anna; Auvinen, Anssi; Raitanen, Jani; Schoemaker, Minouk J.; Christensen, Helle C.; Feychting, Maria; Johansen, Christoffer; Klæboe, Lars; et al. (2007). "Mobile phone use and risk of glioma in 5 North European countries". International Journal of Cancer 120 (8): 1769-75.

Röösli, Martin (June 2008). "Radiofrequency electromagnetic field exposure and non-specific symptoms of ill health: A systematic review". Environmental Research 107 (2): 277 287.

Haarala, C; Takio F; Rintee T; Laine M; Koivisto M; Revonsuo A; Hämäläinen H (May 2007). "Pulsed and continuous wave mobile phone exposure over left versus right hemisphere: effects on human cognitive function". Bioelectromagnetics (WileyLiss, Inc) 28(4): 289-95.

Borbély, AA; Huber R; Graf T; Fuchs B; Gallmann E; Achermann P (19 November 1999). "Pulsed highfrequency electromagnetic field affects human sleep and sleep electroencephalogram". Neuroscience Letters (East Park, Ireland: Elsevier Science Ireland)275 (3): 207-10.

Huber, R; Graf T; Cote KA; Wittmann L; Gallmann E; Matter D; Schuderer J; Kuster N; Borbély AA; Achermann P (20 October 2000). "Exposure to pulsed high-frequency electromagnetic field during waking affects human sleep EEG". Neuro Report (Lippincott Williams \& Wilkins, Inc) 11 (15): 3321-5.

Huber, R; Treyer V; Borbély AA; Schuderer J; Gottselig JM; Landolt HP; Werth E; Berthold T; Kuster N; Buck A; Achermann P (December 2002). "Electromagnetic fields, such as those from mobile phones, alter regional cerebral blood flow and sleep and waking EEG". Journal of sleep 
research (Wiley-Liss, Inc) 11 (4): 28995.

Huber, R; Treyer V; Schuderer J; Berthold T; Buck A; Kuster N; Landolt HP; Achermann P (February 2005). "Exposure to pulse-modulated radio frequency electromagnetic fields affects regional cerebral blood flow". The European Journal of Neuroscience (Wiley-Liss, Inc) 21 (4): 1000-6.

1) Hung, CS; Anderson C; Horne, JA; McEvoy, P (21 June 2007). "Mobile phone 'talk-mode' signal delays EEGdetermined sleep onset". Neuroscience Letters (East Park, Ireland: Elsevier Science` Ireland) 421 (1): 82-6.

2) Andrzejak, R; Poreba R; Poreba $M$; Derkacz A; Skalik R; Gac P; Beck B; Steinmetz-Beck A; Pilecki W (August 2008). "The influence of the call with a mobile phone on heart rate variability parameters in healthy volunteers". Industrial health (National Institute of Industrial Health) 46 (4): 409-17.

3) Klauer, S.G., Dingus, T.A., Neale,V.L., Sudweeks, J.D., \& Ramsey, D.J. (2006). The impact of driver inattention on near crash/crash risk: An analysis using the 100-car Naturalistic Driving Study data.(Report No. DOT HS 810 594). Washington DC: National HighwayTraffic Safety Administration.34. Olson, R.L., Hanowski, R.J.,Hickman, J.S., \& Bocanegra, J.(2009). Driver distraction in commercial vehicle operations. Report No. FMCSA-RRR-09-042). Washington DC: US Department of Transportation.

4) http://www.healthyhearing.com/cont ent/articles/Tinnitus/Treatments/475 36-Help-for-ringing-in. viewed in 6/1/2016.

5) http://www.who.int/pbd/deafness/W HO_GE_HL.pdf .viewed in 6/1/2016.

6) http://www.webmd.com/eye-

health/eye-health-dry-eyes. viewed in 6/1/2016.

7) http://rense.com/general76/celkll.htm

8) http://www.nextup.org/pdf/RossAdeyPrBrainInteractio nsWithRFmicrowaveFieldsGeneratedB yMobilePhones.pdf. Viewed in $\underline{18 / 1 / 2016 .}$ 
Table 1: Systemic symptoms attributed to mobile phone use

\begin{tabular}{|c|c|c|c|}
\hline Symptoms & Felt & Not felt & Total \\
\hline Ear: & & & \\
\hline $\begin{array}{l}\text { 1.Tinnitus after use of } \\
\text { mobile }\end{array}$ & $362(52.3 \%)$ & $330(47.7 \%)$ & $692(100 \%)$ \\
\hline 2. Hearing loss & $260(37.6 \%)$ & $432(62.4 \%)$ & $692(100 \%)$ \\
\hline $\begin{array}{l}\underline{\text { Eye }} \\
\text { Eye dryness and strain }\end{array}$ & $533(77 \%)$ & $159(23)$ & $692(100 \%)$ \\
\hline$\frac{\text { CNS }}{\text { 1.Insomnia }}$ & $505(73 \%)$ & $187(27 \%)$ & $692(100 \%)$ \\
\hline $\begin{array}{l}2 . \quad \text { Lack of } \\
\text { concentration }\end{array}$ & $563(81.4 \%)$ & $129(18.6 \%)$ & $692(100 \%)$ \\
\hline 3. Memory loss & $430(62.1 \%)$ & $262(37.9 \%)$ & $692(100 \%)$ \\
\hline 4. Headache & $363(52.5 \%)$ & $329(47.5 \%)$ & $692(100 \%)$ \\
\hline $\begin{array}{l}\text { Cardiac } \\
\text { 1. Palpitation }\end{array}$ & $205(29.6 \%)$ & $487(70.4 \%)$ & $692(100 \%)$ \\
\hline Musculoskeletal & & & \\
\hline $\begin{array}{l}\text { 1.Pains in hand fingers } \\
\text { and wrist after due to } \\
\text { mobile }\end{array}$ & $438(63.3 \%)$ & $254(36.7 \%)$ & $692(100 \%)$ \\
\hline $\begin{array}{l}\text { 2. Pains in the neck } \\
\text { after mobile use }\end{array}$ & $536(77.5)$ & $156(22.5 \%)$ & $692(100 \%)$ \\
\hline $\begin{array}{l}\text { 3. Pain in lower limb } \\
\text { while keeping mobile } \\
\text { at waist belt level }\end{array}$ & $117(16.9 \%)$ & $575(83.1)$ & $692(100 \%)$ \\
\hline
\end{tabular}


Table ( 2 ) Mobile phone use and insomnia considering age and smoking habits

\begin{tabular}{|c|c|c|c|c|c|}
\hline Age group & Smoking & \multicolumn{2}{|l|}{ Insomnia } & Total & $X^{2}-p$ value \\
\hline & & $\begin{array}{l}\text { Yes } \\
\text { Count }(\%)\end{array}$ & $\begin{array}{l}\text { No } \\
\text { Count }(\%)\end{array}$ & & \\
\hline \multirow[t]{2}{*}{-18} & Yes & $18(85.7)$ & $3(14.3)$ & $21(100.0)$ & \multirow{2}{*}{$\begin{array}{l}6.817-< \\
0.05\end{array}$} \\
\hline & No & $27(52.9)$ & $24(47.1)$ & $51(100.0)$ & \\
\hline \multirow[t]{2}{*}{-25} & Yes & $71(73.2)$ & $26(26.8)$ & $97(100.0)$ & \multirow{2}{*}{$\begin{array}{l}0.362-> \\
0.05\end{array}$} \\
\hline & No & 153(69.9) & $66(30.1)$ & $219(100.0)$ & \\
\hline \multirow[t]{2}{*}{-35} & Yes & $72(87.8)$ & $10(12.2)$ & $82(100.0)$ & \multirow{2}{*}{$\begin{array}{l}8.625- \\
<0.05\end{array}$} \\
\hline & No & $93(70.5)$ & $39(29.5)$ & $132(100.0)$ & \\
\hline \multirow[t]{2}{*}{$>35$} & Yes & $21(87.5)$ & $3(12.5)$ & $24(100.0)$ & \multirow{2}{*}{$\begin{array}{l}1.457- \\
0.05\end{array}$} \\
\hline & No & $50(75.8)$ & $16(24.2)$ & $66(100.0)$ & \\
\hline
\end{tabular}

Table (3 ): Mobile phone use and lack of concentration considering age and smoking status

\begin{tabular}{|c|c|c|c|c|c|}
\hline Age group & Smoking & \multicolumn{2}{|c|}{ Lack of concentration } & Total & $X^{2}-p$ value \\
\hline & & $\begin{array}{l}\text { Yes } \\
\text { Count }(\%)\end{array}$ & $\begin{array}{l}\text { No } \\
\text { Count }(\%)\end{array}$ & & \\
\hline \multirow[t]{2}{*}{-18} & Yes & $18(85.7)$ & $3(14.3)$ & $21(100.0)$ & \multirow{2}{*}{$\begin{array}{l}2.690-> \\
0.05\end{array}$} \\
\hline & No & $34(66.7)$ & $17(33.3)$ & $51(100.0)$ & \\
\hline \multirow[t]{2}{*}{-25} & Yes & $85(87.6)$ & $12(12.4)$ & $97(100.0)$ & \multirow{2}{*}{$\begin{array}{l}1.021-> \\
0.05\end{array}$} \\
\hline & No & $170(77.6)$ & $49(22.4)$ & $219(100.0)$ & \\
\hline \multirow[t]{2}{*}{-35} & Yes & $73(89.0)$ & $9(11.0)$ & $82(100.0)$ & \multirow{2}{*}{$\begin{array}{l}4.318- \\
<0.05\end{array}$} \\
\hline & No & $111(84.1)$ & $21(15.9)$ & $132(100.0)$ & \\
\hline \multirow[t]{2}{*}{$>35$} & Yes & $22(91.7)$ & $2(8.3)$ & $24(100.0)$ & \multirow[b]{2}{*}{$\begin{array}{l}2.784-> \\
0.05\end{array}$} \\
\hline & No & $50((75.7)$ & $16(24.4)$ & $66(100)$ & \\
\hline
\end{tabular}


Table (4 ): Mobile phone use and leg pain considering age and smoking status

\begin{tabular}{|c|c|c|c|c|c|}
\hline Age group & Smoking & \multicolumn{2}{|l|}{ Leg pain } & Total & $X^{2}-p$ value \\
\hline & & $\begin{array}{l}\text { Yes } \\
\text { Count }(\%)\end{array}$ & $\begin{array}{l}\text { No } \\
\text { Count }(\%)\end{array}$ & & \\
\hline \multirow[t]{2}{*}{-18} & Yes & $11(52.4)$ & $10(47.6)$ & $21(100.0)$ & \multirow{2}{*}{$\begin{array}{l}13.605- \\
<0.05\end{array}$} \\
\hline & No & $6(11.8)$ & $45(88.2)$ & $51(100.0)$ & \\
\hline \multirow[t]{2}{*}{-25} & Yes & $27(27.8)$ & $70(72.2)$ & $97(100.0)$ & \multirow{2}{*}{$\begin{array}{l}19.840- \\
<0.05\end{array}$} \\
\hline & No & $19(8.7 \%)$ & $200(91.3)$ & $219(100.0)$ & \\
\hline \multirow[t]{2}{*}{-35} & Yes & $16(19.5)$ & $66(80.5)$ & $82(100.0)$ & \multirow{2}{*}{$\begin{array}{l}.459- \\
0.05\end{array}$} \\
\hline & No & $21(15.9)$ & $111(84.1)$ & $132(100.0)$ & \\
\hline \multirow[t]{2}{*}{$>35$} & Yes & $5(20.8)$ & $19(79.2)$ & $24(100.0)$ & \multirow[t]{2}{*}{$.081->0.05$} \\
\hline & No & $12(18.2)$ & $54(81.8)$ & $66(100.0)$ & \\
\hline
\end{tabular}

Table (5 ): Mobile phone use and palpitation considering age and smoking status

\begin{tabular}{|c|c|c|c|c|c|}
\hline Age group & Smoking & Lack of col & tration & Total & $\mathrm{X}^{2}-\mathrm{p}$ value \\
\hline & & $\begin{array}{l}\text { Yes } \\
\text { Count (\%) }\end{array}$ & $\begin{array}{l}\text { No } \\
\text { Count (\%) }\end{array}$ & & \\
\hline-18 & Yes & $10(47.6)$ & $11(52.4)$ & $21(100.0)$ & $5.818-$ \\
\hline & No & $10(19.6)$ & $41(80.4)$ & 51(100.0) & $<0.05$ \\
\hline-25 & Yes & $32(33.0)$ & $65(67.0)$ & 97(100.0) & $1.611->$ \\
\hline & No & $57(26.0)$ & $162(74.0)$ & $219(100.0)$ & 0.05 \\
\hline-35 & Yes & $31(37.8)$ & $51(62.2)$ & $82(100.0)$ & $3.022-$ \\
\hline & No & $35(26.5)$ & $97(73.5)$ & $132(100.0)$ & 0.05 \\
\hline$>35$ & Yes & $8(33.3)$ & $16(66.7)$ & $24(100.0)$ & $.000-$ \\
\hline & No & $22(33.3)$ & $44(66.7)$ & $66(100.0)$ & 0.05 \\
\hline
\end{tabular}

